\title{
The Use of Integrated Pulmonary Index in Cardiopulmonary Resuscitation
}

\author{
(1D) Sevilay Sema Ünver, (D) Asım Kalkan
}

University of Health Sciences, Okmeydanı Training and Research Hospital, Department of Emergency Medicine, Istanbul, Turkey

Keywords: Cardiopulmonary resuscitation, integrated pulmonary index, return of spontaneous circulation

\section{Dear Editor,}

Recent studies have shown that various biomedical devices are used for return of spontaneous circulation (ROSC). End-tidal carbon dioxide (ETCO2) measurement in cardiopulmonary resuscitation (CPR) is also included in the guidelines as the gold standard for ROSC (1). Kalkan et al., (2) measured the blood flow in abdominal organs and the brain using near infrared spectrophotometry in CPR and demonstrated the importance of increasing values in showing ROSC. One of these devices, Capnostream 20p (Capnostream ${ }^{\circledR}$ 20, Oridion, Jerusalem, Israel) measures respiratory rate, pulse rate, saturation and ETCO2, and gives a mathematical value [integrated pulmonary index (IPI)] for assessing the patient's ventilation level and associated tissue perfusion. This device provides numerical values between 1 and 10 . Values less than 7 indicate worsening of breathing and tissue perfusion, and advanced airway requirements (3). Studies have also reported that patients with an IPI score less than 4 require advanced airway support (4). Our study was planned on the basis that ETCO2 is used to calculate IPI values and is capable of predicting spontaneous circulation. Our aim was to investigate initial IPI values in cases of out-of-hospital cardiac arrest, together with the IPI trend during CPR and its association with absence of presence of ROSC. We planned to enroll 50 patients with or without ROSC. Our aim was to measure IPI values in patients with non-hospital cardiac arrest and to analyze whether these were predictive of ROSC. Our basic hypothesis is that IPI values at time of admission are low. We anticipated that these would increase after proper CPR, and that as IPI values increased, tissue perfusion would be established and spontaneous circulation would be restored. Spontaneous circulation was not restored in six of the first eight patients. IPI values during admission and throughout CPR were measured as 1 (however, ETCO2 values were increasing, showing that these patients had no intubation problems). ROSC was achieved in the remaining two patients, but IPI values were still 1. No increase was observed in measured values in any of our patients. However, under normal conditions, appropriate CPR establishes both respiration and circulation. Measurements may be expected to increase in the absence of any pulmonary pathology. We therefore suspected the possibility of an error in our methodology, and we have reviewed the details of the IPI. By using Ambu-bag, we ventilate the patient 8-10 times per minute and ensure the respiratory rate among the four parameters considered in IPI. We also provide heart rate with active heart massage and saturation by giving oxygen with advanced airway. The ETCO2 level is obtained with variable values in the trend graph. IPI values being a constant 1, although different levels might be expected with different practitioners, derives from the fact that the IPI shows the presence of a vital critical level, at the same algorithmic level, in the loss of one of these four functions in the patient. We do not think IPI will also be 
able to predict spontaneous circulation in CPR, although this device is highly suitable for showing respiratory status and for deciding intubation. However, further studies with larger patient populations may support our hypothesis.

\section{Ethics}

Peer-review: Internally peer-reviewed.

\section{Authorship Contributions}

Surgical and Medical Practices: S.Ü., Concept: A.K., Design: A.K., Data Collection or Processing: S.Ü., Analysis or Interpretation: S.Ü., Literature Search: S.Ü., Writing: S.Ü.

Conflict of Interest: No conflict of interest was declared by the authors.
Financial Disclosure: The authors declared that this study received no financial support.

\section{References}

1. Link MS, Berkow LC, Kudenchuk PJ, Halperin HR, Hess EP, Moitra VK, et al. Part 7: adult advanced cardiovascular life support: 2015 American heart association guidelines update for cardiopulmonary resuscitation and emergency cardiovascular care. Circulation 2015;15:132:e385.

2. Kalkan A, Bilir O, Ersunan G, Ozel D, Tas M, Memetoglu ME. Abdominal oxygen saturation for monitoring return of spontaneous circulation in outof-hospital cardiac arrest using near infrared spectrophometry. Am J Emerg Med 2015;33:344-8.

3. Ronen M, Weissbrod R, Salinas J. Pilot evaluation if the IPI integrated pulmonary index ${ }^{\mathrm{TM}}$ on trauma subjects. Abstract presented at 2010 ATACCC Conference, August 17, 2010.

4. Ronen M, Weissbrod R, Overdyk FJ, Ajizian S. Smart respiratory monitoring: clinical development and validation of the IPITM (Integrated Pulmonary Index) algorithm. Clin Monit Comput 2017;31:435-42. 